\title{
PLOS $\mid$ submission
}

S13 Table Enrichment statistics and general linear model coefficients for squared Height association z-scores differences between adipose tissue, epidermal tissue, lymphoblastoid cell lines (LCL) and whole blood eQTLs, and matching control variants.

\begin{tabular}{|c|c|c|c|c|c|c|c|}
\hline annotation & & $\beta$ & $\beta$ (low 95\%) & $\beta$ (high 95\%) & $p$ & $\pi_{1}$ & $p_{\mathrm{MW}}$ \\
\hline \multirow{2}{*}{ Adipose } & eQTL & 0.19 & 0.055 & 0.32 & 0.0057 & 0.20 & \multirow{2}{*}{$4.77 \mathrm{E}-08$} \\
\hline & control & -0.093 & -0.15 & -0.037 & 0.0011 & 0.17 & \\
\hline \multirow{2}{*}{ Epidermal } & eQTL & 0.16 & 0.056 & 0.26 & 0.0026 & 0.24 & \multirow{2}{*}{$5.88 \mathrm{E}-08$} \\
\hline & control & -0.058 & -0.11 & -0.0024 & 0.041 & 0.20 & \\
\hline \multirow{2}{*}{ LCL } & eQTL & 0.30 & 0.18 & 0.43 & $3.19 \mathrm{E}-06$ & 0.24 & \multirow{2}{*}{$3.06 \mathrm{E}-16$} \\
\hline & control & -0.18 & -0.24 & -0.12 & $1.51 \mathrm{E}-09$ & 0.14 & \\
\hline \multirow{2}{*}{ Whole blood } & eQTL & 0.18 & 0.04 & 0.33 & 0.012 & 0.22 & \multirow{2}{*}{0.00032} \\
\hline & control & -0.0077 & -0.071 & 0.055 & 0.81 & 0.16 & \\
\hline \multirow{3}{*}{ All } & prox & 0.24 & 0.17 & 0.31 & $1.04 \mathrm{E}-11$ & 0.25 & 0.023 \\
\hline & dist & 0.26 & 0.17 & 0.34 & $1.16 \mathrm{E}-08$ & 0.21 & 0.98 \\
\hline & eQTL & 0.28 & 0.22 & 0.34 & $4.26 \mathrm{E}-21$ & 0.22 & $6.86 \mathrm{E}-29$ \\
\hline
\end{tabular}

$\bar{\beta}$ is the mean effect size over the general linear model replicas with functional genetic affiliation covariates; $p$ is the corresponding unadjusted p-value (see methods for more details); $\pi_{1}$ is the estimated proportion of non-null associations; $p_{\mathrm{MW}}$ is the unadjusted Mann-Whitney test p-value for differences in association chi-squared between eQTL and respective matched control variants; prox stands for proximal eQTLs, dist for distal eQTLs. 